\title{
O BRINCAR E SUAS REIAÇÕES COM O DESENVOLVIMENTO
}

\author{
Playing and its Relationship with Development
}

\author{
Maria Ângela Camilo Marques Pereira ${ }^{1}$ \\ Deise Matos do Amparo ${ }^{2}$ \\ Sandra Francesca Conte de Almeida ${ }^{3}$
}

\section{Resumo}

A literatura psicológica sobre o brincar e o seu papel no desenvolvimento infantil é bastante vasta, o que enfatiza sua importância. Há indicações de que, para que se compreenda o brincar da criança, sobretudo na escola, deve-se levar em consideração tanto os períodos de desenvolvimento quanto as etapas transicionais em um determinado período. Este artigo focaliza aspectos teóricos do brincar e sua relação com o desenvolvimento infantil, considerando, de forma crítica e integrada, perspectivas de autores clássicos, tais como Piaget, Wallon, Vygotsky e Leontiev. Conclui-se que a relação entre desenvolvimento, brincadeira e cultura não pode ser ignorada. O brincar, seja do ponto de vista social seja do individual, não é uma atividade secundária no desenvolvimento infantil, ao contrário, é ela que fornece os principais meios para as articulações entre desenvolvimento pessoal e sócio-histórico. Além disso, do ponto de vista do cotidiano escolar, emerge a necessidade de discussões sobre um tempo pedagógico, envolvendo o brincar, que esteja mais articulado com as possibilidades objetivas e subjetivas da criança no seu desenvolvimento, mesmo que a escola esteja principalmente voltada para a aquisição do conhecimento.

Palavras-chave: Brincar; Desenvolvimento; Escola.

\section{Abstract}

The psychological literature on play and its importance on children's development is quite broad, that emphasizes its importance. It seems that, in order to understand children's playing, particularly conceming school, it should be taken into account both development stages and the transitional phases within these stages. This article focus theoretical aspects of playing and its relationship with infant development, considering the perspective of authors such as Piaget, Wallon, Vygotsky e Leontiev in a critical and integrated manner. It concludes by stating that the relationship between development, playing and culture cannotbe ignored. Playing, from both social and individual perspective, is not a secondary activity in children's development. On the contrary, playing activities give the means to articulate personal and socio-historical development. Besides, from the point of view of school daily life, there is the emergence of the need to discuss about a pedagogical time that includes playing. This should go togetherwith the objective and subjective possibilities of children and their development, even considering that schools are more concerned with knowledge acquisition.

Keywords: Play; Development; School.

1 Psicóloga. Mestre em Psicologia pela Universidade Católica de Brasília.

2 Professora-Doutora dos cursos de Graduação e Mestrado em Psicologia da Universidade Católica de Brasília. Psicanalista Endereço para correspondência: Universidade Católica de Brasília - UCB, Pró-reitoria de Pós-graduação e Pesquisa. SGAN, Módulo B, W5 Norte - Campus II - CEP: 70790-160, Brasília DF. deise@ucb.br

3 Professora-Doutora do Mestrado em Psicologia da Universidade Católica de Brasília. Professora aposentada do Instituto de Psicologia da Universidade de Brasília. Psicanalista. 


\section{Introdução}

A palavra brincar provém do substantivo masculino brinco, um adorno ou enfeite, enquanto esta, brinco (jóia), provém do latim vinculum, laço (Cunha, 1982).

Ao consultar-se o dicionário (Ferreira, 1999), depara-se com um extenso e variado grupo de palavras destinado a dar a idéia do que pode significar brincar. Tem-se a idéia de brincar como sendo distração, entretenimento, diversão, agitação, alegria, movimento, fazer-de-conta, excesso (por exemplo, de adorno), jocosidade. Dentre os principais significados para brincadeira destacamse: ato ou efeito de brincar; divertimento, sobretudo entre crianças, brinquedo, jogo; folguedo, festa, festança.

Quanto ao significado de jogar, encontra-se no mesmo dicionário principalmente palavras cujo sentido gira em torno de: entrega ao ato de jogar, participação de modo combinado, aventurar-se, arriscar-se, investir, precipitar-se, instigar, fazer-de-conta, acatar ou condizer, desempenhar, divertir-se, harmonizar-se, brincar. Enquanto que para jogo encontram-se os seguintes termos e explicações: atividade física ou mental organizada por um sistema de regras que define a perda ou 0 ganho; manha, astúcia, ardil; regras que devem ser observadas quando se joga.

Em Huizinga (1993), encontra-se uma detalhada investigação etimológica e cultural das designações da função lúdica. Do latim ludusabrange tanto os jogos infantis, a recreação, como também as competições, as representações litúrgicas e teatrais e os jogos de azar. Ludus provém de ludere, que cobre todo o terreno do jogo e deixa a marca da não-seriedade e do simulacro. Este autor aponta que em todas as línguas que pesquisou a designação ludus foi suplantada pelo derivado jocus (gracejar, troçar).

Elkonin (1998), ao levantar significados culturais do jogo, indica que o vocábulo é utilizado para fazer referência a muitos fenômenos distintos, desde 0 ato do bebê manipular algum objeto até os jogos adultos, tais como o xadrez ou 0 futebol, por exemplo.

De fato, autores advertem que ao longo dos tempos e por meio dos mais distintos trabalhos, jogar e brincar tendem a se misturar e a adquirir um mesmo significado mais do que uma diferenciação. Dantas (2002) esclarece que brincar e jogar são termos distintos, em português, embora nas línguas de cuja cultura sejamos devedores eles estejam fundidos, como o francês jouer e 0 inglês play. Por essa razão, quase sempre se desperdiça uma diferenciação de ordem psicogenética permitida em nossa língua.

É vasta a literatura psicológica que aborda o brincar, em razão do seu importante papel no desenvolvimento da criança. Neste artigo, pretende-se apresentar uma "visão panorâmica" das contribuições e estudos de alguns dos principais autores da Psicologia do Desenvolvimento sobre o brincar e suas relações com o desenvolvimento infantil, sobretudo nas idades pré-escolar e escolar.

\section{O brincar e o desenvolvimento}

\section{Piaget, uma perspectiva cognitivista}

Os estudos de Piaget (1964/1971) sobre o desenvolvimento infantil estão predominantemente voltados para o desenvolvimento cognitivo. A inteligência se desenvolve em uma seqüência de estágios relacionados com a idade da criança. As atividades, intelectual e biológica, são partes do processo global pelo qual o organismo adapta-se ao meio e organiza as experiências, frente às transformações que aparecem no mundo interior ou no mundo exterior. A ação humana, que a cada instante sofre desequilíbrio frente às transformações, consiste em um processo contínuo e perpétuo, que se orienta para o equilíbrio por meio de reajustamentos. Piaget (1964/1971) defende uma constituição de sistemas estruturais como chave do desenvolvimento da inteligência, sob um enfoque genético, significando que as funções psicológicas podem ser estudadas em seu processo de formação. Cada estágio do desenvolvimento da inteligência se caracteriza pelo surgimento de estruturas originais, cuja construção o distingue dos estágios anteriores. Porém, no decorrer dos estágios ulteriores, o essencial dessas construções sucessivas permanece como subestruturas, sobre as quais as novas características se constroem. São necessidades e interesses comuns a todas as idades. Piaget deu ênfase à atividade do sujeito na aquisição do conhecimento, assim como acentuou o caráter qualitativo das mudanças no desenvolvimento cognitivo. 
Seis estágios ou períodos do desenvolvimento vão marcar o surgimento das estruturas da inteligência, isto é, "as formas de organização da atividade mental, sob um duplo aspecto: motor ou intelectual, de uma parte, e afetivo, de outra, com suas dimensões individual e social (interindividual)" (Piaget, 1964/1971, p. 13). Os três primeiros constituem o período de lactância, em torno das idades de zero até um ano e meio a dois anos, isto é, anterior ao desenvolvimento do pensamento e da linguagem, e que abrange o estágio dos reflexos e das primeiras emoções, o dos primeiros hábitos motores e primeiras percepções organizadas e sentimentos diferenciados e o estágio da inteligência senso-motora ou prática, em que ocorre uma descentralização das ações em relação ao próprio corpo e uma gradual coordenação das ações, entre os dezoito e os vinte e quatro meses. Este estágio, o sensório-motor, é marcado pela formação da função simbólica ou semiótica. Gradualmente a criança vai adquirindo a linguagem e a imagem mental e mostra capacidade de representação simbólica, ou seja, adquire a capacidade de representação das coisas. Começam a acontecer as primeiras tentativas de desenho e representação gráfica.

O quarto estágio que abrange, em geral, as idades de dois a sete ou até oito anos, define-se como estágio pré-operatório. Nele, Piaget prevê um primeiro nível ou subestágio, de dois a quatro anos e um segundo subestágio de cinco a seis. É o estágio da inteligência intuitiva, dos sentimentos interindividuais espontâneos e das relações sociais de submissão ao adulto.

As idades de sete a onze, doze anos estão compreendidas no quinto estágio, o das operações intelectuais concretas (começo da lógica), bem como dos sentimentos morais e sociais de cooperação. Antes desse estágio, quando são mais novas, as crianças não conseguem abstrair posições em classes, para percebê-las recorre às posições concretas dos objetos. Entre sete e oito anos, em média, ocorre uma decisiva transformação no que concerne à elaboração dos seus instrumentos de conhecimento. Caracteriza-se, principalmente, pela aquisição das operações concretas, ou seja, uma capacidade de "fazer dentro da cabeça", o que antes ela teria que concretizar por ações reais. A criança consegue pensar sobre as coisas, pode contar mentalmente em seqüência, em lugar de se valer do objeto e consegue pensar nas relações entre classes de coisas. No fim do período das operações concretas, as crianças adquirem capacidade de resolver problemas mentais e de combinar e dividir conceitos de classe.

As operações concretas permitem a prática dos jogos com regras, quando então buscam vencer, quase sempre em razão de um desejo de demonstrar a sua inteligência (Elkind, 1972).

Nessa fase do desenvolvimento, em que o egocentrismo se manifesta, a criança também expressa paixão pelas histórias de mistério, aventura e magia, interessa-se pelas séries de televisão, especialmente pelos super-heróis, que mostram modalidades de mundos bem particulares.

O sexto estágio compreende a adolescência. É o estágio das operações intelectuais abstratas, da formação da personalidade e da inserção afetiva e intelectual na sociedade dos adultos. É por volta de onze a doze anos que ocorre o que Piaget denomina operações formais, que se caracteriza pela possibilidade de transpor as operações lógicas do plano de manipulação concreta para o plano das idéias. Elas podem ser expressas em algum tipo de linguagem (linguagem das palavras, dos símbolos matemáticos, por exemplo), prescindindo do apoio de uma percepção direta de uma experiência ou de uma crença.

A classificação dos jogos, elaborada por Piaget, corresponde às características das estruturas mentais: os jogos de exercício sensório-motor, os jogos simbólicos e os jogos de regras.

Os jogos de exercício sensório-motor iniciam a atividade lúdica da criança, surgindo quando ela pratica movimentos simples, cujo prazer do funcionamento é a sua própria finalidade. Os exercícios consistem em repetição de gestos simples, que começam com a organização das percepções e hábitos do bebê e predominam durante todo 0 período da inteligência sensório-motora, embora se mantenham durante toda a infância e se prolonguem até a fase adulta.

Os jogos simbólicos destacam-se com a predominância da atividade da criança de assimilar e transformar o real, tendendo a reproduzi-lo em função dos seus desejos. Nos jogos de faz-de-conta, a criança se auto-expressa, realiza seus sonhos e fantasias, revelando conflitos, medos e angústias e aliviando tensões e frustrações. Eles preponderam entre os dois e os seis anos, período que corresponde à fase pré-escolar. 
O simbolismo decresce entre os sete e os doze anos. Nesta idade, correspondente à fase escolar, a atividade lúdica da criança consiste mais em desenhos, trabalhos didáticos, representações teatrais e atividades de jogos de construção e de regras, inclusive os de computador. Os jogos de regras começam a se manifestar por volta dos cinco anos e se desenvolvem, passando a preponderar entre os sete e doze anos. O jogo de regras é de caráter social e consiste em um conjunto de leis impostas pelo grupo, cujo descumprimento é penalizado. Pressupõe a existência de parceiros, competição e um conjunto de obrigações. Note-se que a decadência da fase do pensamento egocêntrico da criança possibilita que ela desenvolva relacionamentos afetivosociais, permitindo o surgimento dos jogos de regra. Estes passam a fazer parte da vida do indivíduo, inclusive na fase adulta.

É importante destacar que a teoria do desenvolvimento cognitivo, de Piaget, fornece noções claras de que existem peculiaridades em cada um dos estágios evolutivos, sem deixar de transmitir uma idéia de transitividade.

\section{Wallon, Vygotsky e Leontiev, uma perspectiva materialista-dialética}

Wallon, Vygotsky e Leontiev estão ligados a uma mesma fonte filosófica, o materialismo dialético, o que possibilita identificações importantes nos fundamentos dos seus trabalhos. Duas dessas identificações são: a recusa dos autores em enquadrar o desenvolvimento em esquemas rígidos e lineares e a consideração de que o jogo é um espaço de liberdade para a criança construir um mundo simbólico, ao mesmo tempo em que se constitui como um espaço onde ela se obriga a seguir determinadas regras. Este é o pensamento dialético que, desde a sua origem até hoje, caracteriza-se pela arte do diálogo e da discussão, porque implica as contradições da realidade e a mediação, em lugar da certeza ou de uma solução teórica (Konder, 2000). O interesse comum desses autores situase na compreensão de uma psicologia do desenvolvimento como resultado dos estudos do funcionamento cognitivo, social e afetivo do ser humano, enquanto inserido em uma realidade histórica e cultural concreta.

\section{H. Wallon}

Wallon (1941/1995;1975), contrariamente ao pensamento largamente difundido na Psicologia, que, como ele dizia, parecia considerar a criança, nos primeiros anos de vida, fechada em si mesma, em um estado que Piaget chama de "autismo", defende o conceito de ambiência, que envolve a criança, tecendo-a por meio da linguagem e da fala. Seu estudo enfatiza a vinculação entre as dimensões afetiva, cognitiva e motora e a compreensão da pessoa assim constituída por meio de uma interação dialética.

A afetividade ocupa lugar central na psicologia genética de Wallon, tanto na perspectiva da construção da pessoa quanto na do conhecimento. Ambas se iniciam ao longo do primeiro ano de vida quando, então, a afetividade se resume praticamente às manifestações fisiológicas da emoção, constituindo-se, portanto, no "ponto de partida do psiquismo", como assinala Dantas (1992), sendo este resultante de uma síntese entre o orgânico e o social. A consciência afetiva corresponde à sua primeira manifestação, sendo a forma pela qual o psiquismo emerge da vida orgânica. É à primeira manifestação emocional do bebê que se instaura um vínculo imediato entre o ambiente social e a criança e garante seu acesso ao universo simbólico da cultura. Tanto as emoções como a motricidade têm papel fundamental no desenvolvimento humano. Wallon as estuda articuladamente, considerando que modulação afetiva e modulação muscular acompanham-se estreitamente e que a alteração de uma corresponde à alteração da outra. Em sua concepção de desenvolvimento, a inteligência é um meio ou instrumento colocado à disposição do desenvolvimento. $\mathrm{O}$ ato mental se desenvolve a partir do ato motor, em seguida passa a inibi-lo sem deixar, no entanto, de ser um ato corpóreo. Portanto, as interações entre as dimensões motora, mental e emocional estão em constante movimento e, a cada configuração dessas dimensões, são criadas novas possibilidades, ou seja, novos recursos motores, afetivos, cognitivos, que se revelam em atividades que convivem, ao mesmo tempo, com as atividades adquiridas anteriormente, assim como preparam a mudança para o estágio posterior. Desse modo, os estágios do desenvolvimento, discutidos por Wallon, só podem ser compreendidos em uma sucessão temporal, posto que a existência de um 
é que faz emergir o estágio seguinte, uma vez que a criança interage com o meio a partir dos recursos dos quais dispõe, sempre considerada a dimensão social e histórica dessa interação.

A primeira fase do desenvolvimento da pessoa, nomeada impulsiva, inicia-se com o nascimento e abrange movimentos globais, bruscos e desordenados, de enrijecimento e relaxamento da tensão muscular. As relações afetivas com o meio começam a predominar e, a partir dos seis meses, uma gama de trocas emotivas e de sinalizações expressivas recíprocas pode estar formada. Em razão dessas mudanças, é chamada fase emocional. Essa fase, ainda que sob o domínio emocional, prepara a fase seguinte, a fase sensório-motora, com início em torno do oitavo ao décimo mês. Predominam atividades exploratórias, de agarrar, apanhar, pegar objetos e em seguida largá-los, rasgar, espalhar. Em torno do oitavo ou décimo mês ocorre o comportamento de manipulação das formas de uma estrutura, sua decomposição e composição, por exemplo. A criança começa a apresentar gradativos progressos em relação ao equilíbrio. Surge a palavra que pode acompanhar os gestos. As perguntas são sobre o objeto fazendo denotar que, para ela, a palavra se confunde com o objeto, quer reclamando por ele, quer evocando a sua imagem. É o período do voluntarismo e do sincretismo. A palavra, tal como a mão, é utilizada para investigações objetivas por meio das realidades e das significações do mundo exterior. Nessa fase, a palavra tem, principalmente, um papel exploratório. Posteriormente virá a ter outros usos.

O estágio categorial compreende idades de seis a onze anos. Nessa fase concorre 0 auxílio do período anterior, de diferenciação do eu. Ocorre um predomínio de atividades de exploração mental do mundo físico, por meio de agrupamento, seriação, classificação. Suas atividades representam os vários níveis de abstração para chegar ao pensamento categorial e a criança começa a organizar o mundo físico em categorias bem mais definidas.

Nessa fase, ela pode aprender a distinguir unidades e conjuntos, aprender a ler e combinar letras e números. Consegue classificar objetos, por meio de semelhanças e diferenças. A atividade categorial possibilita à criança uma compreensão mais nítida de si mesma.

Sobre a atividade de brincar, Wallon (1941/1995) afirma que, provavelmente, essas ati- vidades receberam o nome de jogo por uma assimilação do que é o jogo para o adulto. Mas Wallon contesta tal assimilação, pois se o jogo, para 0 adulto, é lazer, para a criança é toda a atividade. $\mathrm{O}$ autor baseia-se em Kant e afirma ser o jogo uma finalidade sem fim, posto que não visa a um produto externo a ele, tornando-se uma atividade enfadonha e perdendo o caráter de jogo quando se torna utilitária.

Uma vez que os estágios de maturação já foram alcançados, o que o adulto faz é uma regressão consentida. A criança, por sua vez, executa essa mesma atividade como uma porta libertadora das atividades e facilitadora do seu desenvolvimento. Sem renunciar ou negar as necessidades práticas, o jogo as pressupõe, mas não deixa de incorrer contra as disciplinas ou tarefas impostas ao homem. Somente há satisfação no jogo quando a criança pode momentaneamente subtrair o exercício de uma função às imposições ou às limitações que ela normalmente experimenta nas atividades. Wallon define o jogo em uma perspectiva dialética, que resulta da oposição entre, de um lado, atividade libertada, e, de outro, aquelas atividades às quais o jogo se integra; dessa oposição o jogo evolui e as supera, para poder realizar-se. $\mathrm{O}$ autor fala dos paradoxos que o jogo contém. Ao mesmo tempo em que o jogo é espaço de liberdade para a criança construir um mundo simbólico, a ela impõe seguir regras (do jogo).

Wallon (1941/1995) explica os jogos distribuídos por características: a) jogos funcionais abrangem movimentos simples, de pernas, braços, produção de ruídos. Sua descrição inclui o aspecto de preparação para fases futuras do desenvolvimento e o fato de serem encontrados também em outras espécies; b) jogos de ficção - ainda nos primeiros tempos da infância, tais como brincar com boneca, montar um cabo de vassoura como se fosse um cavalo. Apontam para um tipo de brincadeira na qual intervém uma atividade cuja interpretação pela criança é bem mais complexa, em comparação com os jogos funcionais; c) jogos de aquisição - a criança se torna mais exploratória, observa, escuta, esforça-se para perceber e compreender coisas, seres, cenas, imagens; d) jogos de fabricação - a criança encontra prazer em reunir, combinar, transformar e criar novos objetos. Nesses jogos quase sempre se combinam ficção e aquisição, como, por exemplo, quando a criança constrói com blocos e o resultado não é meramente 
uma pilha de blocos, mas pode ser um castelo, para onde ela pode transferir personagens de um outro contexto.

\section{S. Vygotsky}

A abordagem de Vygotsky (1933/1998; Vygotsky, Luria \& Leontiev, 1998) é histórico-cultural, uma vez que a ênfase está nas qualidades que distinguem a espécie humana das demais: transformações e realizações ativas nos diferentes contextos culturais e históricos. Nesta perspectiva, tanto as estruturas sociais como as estruturas mentais têm raízes bem definidas como produtos bastante específicos de níveis determinados do desenvolvimento humano.

$\mathrm{O}$ autor constrói uma psicologia do desenvolvimento enfatizando as relações que os homens estabelecem diariamente, tanto entre si como com a natureza, em sua luta pela sobrevivência, no meio natural e social. Para Vygotsky, a natureza humana é essencialmente social, uma vez que se origina e se desenvolve por meio de uma contínua interação social entre os seres humanos.

Na questão de periodização do desenvolvimento, Vygotsky (citado por Elkonin, 1971/ 2000) define desenvolvimento pela existência de "idades de estabilidade", sendo estas interrompidas pelas "idades de crise", e, estas últimas, pontos de ruptura e de transição no desenvolvimento. Com isto, explicita o processo dialético do desenvolvimento, uma vez que, ao mesmo tempo em que as crises fazem a transição, elas são 0 ponto de ruptura do processo e o resultado é um desenvolvimento humano marcado por etapas qualitativamente diferentes, determinadas pela atividade mediada. Afirma que somente as mudanças internas no curso do próprio desenvolvimento ou as rupturas marcantes durante o desenvolvimento podem fornecer um fundamento confiável para determinar as chamadas "idades" como sendo épocas básicas na formação da personalidade da criança.

Na perspectiva de Vygotsky (1933/1998), o papel da mediação social no desenvolvimento é fundamental, uma vez que nós próprios nos desenvolvemos por meio do outro. Um "outro" que não significa, necessariamente, uma pessoa real, mas a dimensão social da atividade caracteristicamente humana.
Para Vygotsky, o brincar é uma atividade necessária às demandas de maturação e desenvolvimento da criança. Todas as reações humanas mais importantes e radicais são criadas e elaboradas no processo da brincadeira infantil. $\mathrm{O}$ autor enfatiza que a criança é um ser lúdico, está sempre brincando, mas que a sua brincadeira tem um grande sentido prático, correspondendo, com exatidão, à sua idade e aos seus interesses, abrangendo elementos que conduzem à elaboração das necessárias habilidades e hábitos (Vygotsky, 2001).

Vygotsky (1933/1998) destaca uma fundamental característica do brincar diretamente associada ao desenvolvimento: a de intermediar a necessária transição entre estágios do desenvolvimento mental. O brinquedo é uma fonte de desenvolvimento e geradora de zonas de desenvolvimento proximal. Este conceito, conforme Araújo, Almeida e Ferreira (1999, p.73), "remete à preponderância do papel da imitação e da intervenção do adulto em situações interativas lúdicas com a criança. A imitação cria zonas de desenvolvimento proximal e a ação partilhada com 0 adulto (como "outro social" que organiza e acompanha as brincadeiras infantis) assume uma tarefa fundamental no surgimento e na constituição de processos psicológicos qualitativamente diferentes".

Considerando as fases do desenvolvimento infantil, Vygotsky (2001) descreve grupos de brincadeiras. Em um primeiro grupo de brincadeiras estão aquelas em que a criança brinca com objetos como chocalho, lança e apanha objetos, por exemplo, destacando o fato de que, enquanto a criança se entretém com eles, aprende a olhar e ouvir, a apanhar e afastar. Em um grupo seguinte estão as brincadeiras nas quais, por exemplo, a criança se esconde, foge. Essas atividades estão relacionadas à elaboração das habilidades de deslocar-se e de orientar-se no meio, de agir em relação ao mundo dos objetos, mas, também, em relação a um mundo mais amplo, do domínio dos adultos. Nesse grupo, destacam-se os elementos da imitação. Assim, como apontam Araújo, Almeida e Ferreira (1999, p.72), a criança tem a necessidade de agir como vê os outros agirem, de agir como lhe ensinam ou como lhe dizem, mas também como imagina e simboliza o mundo adulto. Entretanto, lembram as autoras, algumas ações estão além de suas capacidades e habilidades e 0 brincar, o brinquedo ou a atividade lúdica surgem "como uma possibilidade de superar a contradi- 
ção existente entre sua necessidade de agir e a impossibilidade de executar as operações exigidas por esta ação, auxiliando a ressignificação da atividade e permitindo o ingresso tanto no universo imaginativo quanto no mundo das regras".

As brincadeiras convencionais formam um terceiro grupo. Elas surgem de regras puramente convencionais e de ações a estas vinculadas, é uma espécie de escola superior de brincadeira.

Ao fim da idade pré-escolar inicia-se o jogar com regras, que se desenvolve durante a vida escolar (Vygotsky, 2001). No período escolar, o "jogar com regras" inclui os jogos desportivos. No que concerne à presença de regras na brincadeira, Vygotsky (2001) aponta para o fato de que toda situação imaginária contém regras, mesmo que de uma forma oculta. De seu lado, todo jogo com regras contém, de forma oculta, uma situação imaginária e regras de comportamento. Deste modo, o brinquedo cria na criança uma nova forma de desejos ensinando-a relacionar seus desejos a um "eu" fictício, ao seu papel no jogo e a regras. Essas condições vividas no jogo são básicas para a ação real e um senso moral no futuro.

Para Vygotsky, à medida que a criança interage com o mundo social e histórico ocorre uma mudança no conteúdo subjetivo da atividade lúdica, revelando a dimensão dialética na construção do desenvolvimento e da identidade infantil, o que permite, portanto, afirmar que o brincar não evolui apenas em virtude das dimensões genética e de idades (Araújo, Almeida \& Ferreira, 1999).

\section{A. N. Leontiev}

A natureza sócio-histórica do desenvolvimento do psiquismo humano constitui o pensamento central dos estudos de Leontiev (1959/1972). Ele descreve etapas do desenvolvimento, tendo como objetivo esclarecer o problema teórico das forças motivadoras do desenvolvimento do psiquismo infantil. Segundo o autor, os estágios do desenvolvimento são determinados por uma certa seqüência no tempo (idade), porém não de uma forma fixa ou idealizada. Somente é possível chegar a ter-se uma compreensão das forças que conduzem o desenvolvimento psicológico humano, em qualquer estágio, tendo-se como fundamental o fato de que o lugar que a criança ocupa objetivamente no sistema das relações humanas se alte- ra sob influências das circunstâncias concretas de sua vida, embora esse lugar, por si só, não determine diretamente o desenvolvimento da psique da criança. $\mathrm{O}$ que determina o seu desenvolvimento é a sua própria vida e o desenvolvimento dos processos reais dessa vida.

Para o estudo do desenvolvimento do psiquismo infantil, Leontiev analisa o desenvolvimento da atividade infantil verificando como ela se constrói nas condições concretas de vida, posto que é a evolução da atividade, tanto interna quanto externa, que determina diretamente 0 desenvolvimento do psiquismo da criança.

Discute teoricamente o conceito de atividade tomando como ponto de partida o fato de que o lugar que a criança ocupa, enquanto sujeito no sistema de relações sociais, modifica-se ao longo do seu desenvolvimento. Determinados tipos de atividades são, então, extremamente importantes para o desenvolvimento subseqüente da criança. O brincar é a atividade principal na infância pré-escolar, enquanto que o estudo é a atividade principal no estágio escolar da infância. Em sua teoria, destaca tanto o papel determinante das condições sócio-históricas do desenvolvimento como o papel do desenvolvimento da consciência de si, como indivíduo. Se a vida do sujeito adquire um novo conteúdo, implica que ele compreende o mundo de uma outra forma. Isto faz com que o sentido de uma brincadeira se diferencie em cada fase ou etapa de crescimento. Embora seja comum crianças brincarem de uma mesma brincadeira em idades bem diferentes, o sentido do jogo se diferencia.

Se, para uma criança pequena, o significado principal do jogo estava na própria ação, correr, perseguir, escapar, esconder; para uma criança em estágio de desenvolvimento mais avançado, jogando esse mesmo jogo, teriam maior significado as relações aparentes das pessoas envolvidas. Quem é quem no jogo, seus papéis e funções surgem em primeiro plano, em uma seqüência onde as relações sociais intrínsecas, os momentos morais, os de maior conteúdo emocional, tornam-se o centro das ações.

Em uma fase ainda mais avançada da idade pré-escolar, ocorre uma mudança no conteúdo do papel desempenhado na brincadeira. É quando a criança descobre que a existência do objeto não implica apenas relações do homem com este objeto, mas, também, relações das pessoas entre 
si. Agora, os outros fazem parte do jogo. Por exemplo, o motorista do carro relaciona-se não mais exclusivamente com o carro, mas com o guarda de trânsito, com o passageiro.

A principal mudança que ocorre no brinquedo durante o desenvolvimento é quando os jogos de enredo se transformam em jogos com regras e, em uma fase mais avançada do estágio pré-escolar, eles passam a predominar. Considerando o desenvolvimento do brincar, o jogo, como unidade, sofre transformações, fazendo surgir uma outra modalidade de jogo. Se, antes, nos jogos de enredo, com um papel expresso, a situação imaginánia era explícita e as regras estavam latentes, ainda na fase pré-escolar, em um estágio mais avançado, começa a surgir um tipo de jogo no qual a imaginação e o papel são latentes e as regras passam a ser explícitas, enquanto que a situação imaginária e o papel estão contidos em forma latente (não foram criados por ela). Ratifica sua afirmativa lembrando que estudos e observações já haviam chegado à conclusão de que os jogos com regras surgiam a partir dos jogos de papéis com situação imaginária, que antes eram fartamente praticados (Leontiev, 1998). Além dessa questão, outro aspecto se destaca: os jogadores se subordinam às regras reconhecidamente de ação do jogo. Por exemplo, se pedacinhos de madeira fazem as vezes de pedaços de pão, a regra é fingir comê-los diligentemente. Esta é uma importante precondição para o surgimento da consciência do princípio da própria regra da brincadeira. É sobre esta base que surgem os futuros jogos com regras.

Nos jogos com regras explícitas, a criança dá mais atenção ao objetivo e às regras para alcançá-lo e, não mais, para o papel e a situação lúdica. Isto faz com que a criança tenha uma consciência cada vez mais intensificada em relação ao objetivo da brincadeira. Por exemplo, o jogo da amarelinha tem como objetivo alcançar o "céu" (espécie de lugar máximo do jogo), mas sob condições previamente estabelecidas, como a formulação de uma regra predefinida, uma forma de expressão exterior. Os jogos tradicionais são jogos com regras explícitas, que surgem em etapa mais avançada da fase pré-escolar. Embora o motivo do jogo continue focado no próprio processo lúdico, o objetivo agora é o intermediário entre o processo e a criança. Isto faz com que a atividade lúdica tenda para um certo resultado. Por exemplo, em "pique-pega" a tarefa é correr e o resultado é con- seguir escapar do pegador. Os jogos com objetivos propiciam à criança fazer auto-avaliações. Por exemplo, ao descobrir sua capacidade de correr e de chegar até o objetivo ou avaliar-se, comparando-se com outros ou mesmo fazer comparações com os resultados que alcançou em outros jogos. Neste contexto, a criança começa a avaliar, por si mesma, as suas ações e as dos outros.

Nesse processo de desenvolvimento, também se destacam os jogos de duplo propósito, não apenas pelo aspecto do desenvolvimento mental e compreensão das regras, mas do ponto de vista da personalidade. O dominar as regras significa dominar seu próprio comportamento, aprender a controlá-lo e a subordiná-lo a um propósito definido. Esses jogos também introduzem um momento essencial para o desenvolvimento da psique da criança, que é um elemento moral em sua atividade. Por exemplo, no jogo "pique-cola", ignorar o jogador que foi paralisado é contraposto com 0 motivo moral de ajudar um companheiro. $\mathrm{O}$ autor destaca a importância deste elemento moral ter surgido na própria atividade da criança e não de uma "máxima moral" que ela tenha ouvido.

Na transição do período pré-escolar para o período escolar, destacam-se os "jogos limítrofes", são os jogos dramatizados. Eles parecem mostrar uma completude da fase lúdica em suas formas pré-escolares. Ou seja, mesmo permanecendo como brincadeira, cada vez mais eles vão sendo destituídos de sua motivação inerente.

Os "jogos de dramatização" diferem dos jogos de papel e das primeiras dramatizações porque não buscam refletir as atividades da personagem retratada de forma generalizada. Ao contrário, reproduzem o que é típico nela, sem que haja imitação ou mímica diretamente. Trata-se de uma construção artística deliberada, quando a criança põe em ação alguma idéia inicial. São formas de brincar que possibilitam uma transição para a atividade estética e seu motivo característico, o de afetar outras pessoas.

Outra forma de transição é o "jogo de fantasia”. Nele não há ações, regras ou objetivos, mas a existência de um elemento externo como testemunho da atividade e o que vem a seguir é o devaneio, o sonho. $\mathrm{O}$ autor define que a imagem da fantasia criada tem um valor em si mesmo. Ela evoca sentimentos excitantes e prazerosos na criança. A criança constrói esta fantasia por amor a essas experiências, transferindo o motivo do jogo 
para seu produto, mostrando haver cessado a brincadeira e nascido o devaneio.

Portanto, os jogos de transição são assim chamados por situarem-se no limite dos brinquedos clássicos da pré-escola. Eles preparam diretamente o caminho para os jogos do período escolar. São jogos didáticos em um sentido amplo da palavra e mostram uma transição para a atividade não-lúdica. No estágio escolar, Leontiev destaca a prevalência dos jogos e dos esportes.

\section{Considerações finais}

As perspectivas teóricas em destaque neste artigo consideram as questões do desenvolvimento humano em suas estreitas relações com a vida social. Uma vez que a ação humana é mediada e o indivíduo ou grupo a executa por meio de um código cultural que promove a ligação entre 0 meio sociocultural e o funcionamento mental, a relação entre desenvolvimento, brincadeira e cultura não pode ser ignorada. O brincar, seja do ponto de vista social seja do individual, não é uma atividade secundária no desenvolvimento infantil, ao contrário, é ela que fornece os principais meios para as articulações entre desenvolvimento pessoal e sócio-histórico.

Torna-se então necessário, ao se considerar brinquedos e brincadeiras na escola, que se atente para as relações entre o brincar, 0 desenvolvimento e as questões relacionadas à vida social e cultural da criança. Para que se possa avaliar o interesse de um jogo, desde o ponto de vista do desenvolvimento infantil, é preciso que se tenha alguma idéia dos jogos que, via de regra, são mais adequados aos interesses e habilidades de determinadas idades, assim como o que podem representar para as crianças de uma determinada cultura ou comunidade.

Contudo, além dos significados comuns a determinadas faixas etárias há, ainda, a possibilidade de que o jogo tenha um significado único para cada uma das crianças, em particular. Por exemplo, aquela que tenha perdido um animal ou um ente querido, poderia vir a dar ao jogo uma significação particular. A possibilidade de se atribuir ao brincar um significado que seja comum a várias crianças, significação dada culturalmente e especialmente relacionada à certa etapa do desenvolvimento, ou seja, com a capacidade de realização de determinadas operações na brincadeira não elimina o fato de que a brincadeira possa vir a ter um sentido diferente e único para cada criança. Neste aspecto, a atividade de brincar revela um liame entre o social e o individual, uma interação profunda entre os aspectos subjetivos e os culturais, pela qual o mundo em volta da criança, a escola, em particular, por meio de mediações simbólicas, dentre as quais os jogos, as brincadeiras, fornece as bases sobre as quais a criança irá adquirir e co-construir seus conhecimentos e desenvolver-se emocional, social e cognitivamente.

Como assinala Brougère (2001, p.9), "a imagem do brinquedo sintetiza a representação que uma dada sociedade tem da criança" e esta proposição se aplica, in totum, à escola.

Do ponto de vista do cotidiano escolar, emerge a necessidade de discussões sobre um tempo pedagógico, envolvendo o brincar, que esteja mais articulado com as possibilidades objetivas e subjetivas da criança no seu desenvolvimento, mesmo que a escola esteja principalmente voltada para a aquisição do conhecimento. Com Montagner (1996), pode-se dizer que é uma heresia pensar que o aluno saberá mais e melhor quanto mais tempo ele passar em situações pedagógicas, posto que o tempo do jogo e das brincadeiras é um tempo importante de descobertas e aprendizagens.

É exatamente o brincar que pode mostrar, com mais clareza, as transições do desenvolvimento. Entretanto, não se pode esquecer que o brincar está fortemente vinculado à cultura e à subjetividade da criança (Pereira, 2004). Neste sentido, o lúdico, na escola, não pode ser entendido como um instrumento meramente didático, mas como principal mediador dos processos de desenvolvimento e de aprendizagem, na infância. 


\section{Referências}

Araujo, C. M. M., Almeida, S. F. C. de, \& Ferreira, M. J. A. (1999). O brincar no desenvolvimento e na subjetividade infantil: tema para a atuação profissional. In: Escola Lacaniana de Psicanálise. I Congresso Internacional de Psicanálise e suas conexões. Trata-se uma criança (pp. 7078). Tomo II. Rio de Janeiro: Companhia de Freud.

Brougère, G. (2001). Brinquedo e cultura. São Paulo: Cortez.

Cunha, A. G. (1982). Dicionário etimológico. Rio de Janeiro: Nova Fronteira.

Dantas, H. (1992). Do ato motor ao ato mental: a gênese da inteligência segundo Wallon. In Y. de La Taille (Org). Piaget, Vygotsky, Wallon: teorias psicogenéticas em discussão. São Paulo: Summus.

Dantas, H. (2002). Brincar e trabalhar. In T. Kishimoto (Org.). O brincar e suas teorias. São Paulo: Pioneira Thompson Learning.

Elkind, D. (1972). Crianças e adolescentes. Rio de Janeiro: Zahar.

Elkonin, D. (2000). Sobre o problema dos estágios no desenvolvimento mental da criança. (Tunes D., Trad). Recuperado em 26 jul 2005: www. marxists.org.

Elkonin, D. (1998). Psicologia do jogo. São Paulo: Martins Fontes.

Ferreira, A. B. H. (1999). Aurélio século XXI: o dicionário da língua portuguesa. Rio de Janeiro: Nova Fronteira.
Huizinga, J. (1993). Homo Ludens. São Paulo: Perspectiva.

Konder, L (2000). O que é dialética. São Paulo: Brasiliense.

Leontiev, A N. (1972). O desenvolvimento do psiquismo. São Paulo: Moraes.

Leontiev, A N. (1998). Uma contribuição à teoria do desenvolvimento da psique infantil. In L. S. Vygotsky, A R., Luria, A N., \& Leontiev. Linguagem, desenvolvimento e aprendizagem. São Paulo: Ícone, EDUSP.

Montagner, H. (1996). Acabar com o insucesso na escola. Lisboa: Instituto Piaget.

Pereira, A. C. M. (2004). Brincar é fazer o quê? A atividade de brincar na con cepção da criança. Dissertação de Mestrado em Psicologia, Universidade Católica de Brasília, Brasília.

Piaget, J. (1971). Seis estudos de Psicologia. Rio de Janeiro: Forense.

Vygotsky, L. S. (1998). A formação social da mente. São Paulo: Martins Fontes.

Vygotsky, L S., Luria, A. R, \& Leontiev, A. N. (1998). Linguagem, desenvolvimento e aprendizagem. São Paulo: Ícone.

Vygotsky, L. S. (2001). Psicologia pedagógica. Martins Fontes: São Paulo.

Wallon, H. (1975). Psicologia e educação da infância. Lisboa: Estampa.

Wallon, H. (1995). A evolução psicológica da criança. Lisboa: ed. 70.

Recebido em/received in: 13/09/05 Aprovado em/approved in: 14/02/06 